Florida International University

FIU Digital Commons

Electrical and Computer Engineering Faculty

Publications

4-2014

\title{
Combined Economic and Emission Dispatch Incorporating Renewable Energy Sources and Plug-In Hybrid Electric Vehicles
}

Amin Gholami

Mahdi Jamei

Javad Ansari

Arif I. Sarwat

Follow this and additional works at: https://digitalcommons.fiu.edu/ece_fac

Part of the Electrical and Computer Engineering Commons

This work is brought to you for free and open access by the College of Engineering and Computing at FIU Digital Commons. It has been accepted for inclusion in Electrical and Computer Engineering Faculty Publications by an authorized administrator of FIU Digital Commons. For more information, please contact dcc@fiu.edu. 


\title{
Combined Economic and Emission Dispatch Incorporating Renewable Energy Sources and Plug-In Hybrid Electric Vehicles
}

\author{
Amin Gholami ${ }^{1}$, Mahdi Jamei ${ }^{2}$, Javad Ansari ${ }^{3}$ and Arif I. Sarwat ${ }^{4}$ \\ 1,3Iran University of Science and Technology, Tehran, Iran \\ 2,4Electrical and Computer Engineering of Florida International University, Miami, USA \\ amin_gholami@elec.iust.ac.ir; mjame044@fiu.edu; Javad_ansari@elec.iust.ac.ir; asarwat@fiu.edu
}

\begin{abstract}
Conventional transportation and electricity industries are considered as two major sources of greenhouse gases (GHGs) emission. Improvement of vehicle's operational efficiency can be a partial solution but it is necessary to employ Plug-In Hybrid Electric Vehicles (PHEVs) and Renewable Energy Sources (RESs) in the network to slow the increasing rate of the GHGs emission. However, it is crucial to investigate the effectiveness of each solution. In this paper, a combination of generation cost and GHGs emission of the two mentioned industries, as economic and environmental aspects of using PHEVs and RESs will be analyzed. The effectiveness of five different scenarios of utilizing the mentioned elements is studied on a test system. To have a realistic evaluation, an extended cost function model of wind farm is employed in optimal power dispatch calculations. Particle Swarm Optimization (PSO) algorithm is applied to the combined economic and emission dispatch (CEED) non- linear problem.
\end{abstract}

\section{Keywords}

Economic Dispatch; Emission; Plug-In Hybrid Electric Vehicles (PHEVs); Particle Swarm Optimization (PSO); Smart Grid; Weibull; Wind Farm

\section{Introduction}

In recent years, power industry has faced many economic and environmental issues. Increasing rate of fossil fuels' cost and environmental laws such as The Kyoto Protocol to the United Nations Framework Convention on Climate Change (UNFCCC) and Low Carbon Transition Plan in July 2009 ,whereby must achieve 80 percent all carbon emissions reduction target by 2050 (DECC), forced governments to go towards wide incorporating of renewable energy

Sources. The concern about the depletion of fossil fuels along with their negative environmental impact are the most critical issues in the field of energy that encouraged many researchers for development of new techniques for control and link integration of the power system (Farhadi, M., et al, 2014). Furthermore, the deployment of next-generation plug-in vehicles on the roads, which include plug-in hybrid electric vehicles (PHEVs) and EVs with vehicle to grid (V2G) capability, both called Gridable Vehicle (GV) in this paper, seems to be an appropriate solution to our problem. GVs are rapidly developing and penetrating to the fleet transportation. Since 2008, more than 116,000 highway-capable plug-in electric cars have been sold in the United States through June 2013 (Voelcker, 2013). In 2011, based on the U.S. Department of Energy's (DoE) forecasts, President Barack Obama set the goal for the U.S. to become the first country to have 1 million electric vehicles on the road by 2015 (Mitlitski, 2012).Subsequently, the U.S government has invested a lot of money on this section to accomplish the aims. For example, it has pledged US\$2.4 billion in federal grants to support the development of next-generation electric cars and batteries, and US\$115 million for the installation of electric vehicle charging infrastructure (Mitlitski, 2012).

Effects of GVs from different aspects are studied in many literatures. In (Masoum et al, 2013; Amini et al, 2013), new smart load management (SLM) approach for the coordination of multiple GV chargers in distribution feeders is proposed. In a report of the National Renewable Energy Laboratory (NREL), emission's variation is only considered in several scenarios for charging. It has been represented that using PHEVs will lead to significant reduction in $\mathrm{CO}_{2}$ emission (Parks et al, 2007). Some studies modeled the effect of electricity price and charging mode on electric vehicles' customer behaviour (Amini, M.H. et al, 2012). These vehicles have charge/discharge capability that can influence load profile. In (Kempton and Tomic, 2005), (Kempton and Tomic, 2005), authors surveyed 
the advantage of V2G capability for PHEVs as a reserve to help load shaving and regulation. In (Hadley and Tsvetkova, 2008), effect of GVs on electrical load curve grid, generation capacity and cost has been analyzed. In (Meliopoulos et al, 2009), two studies are presented quantifying the impact of GVs on the power grid. The first study quantifies this impact in terms of (a) primary fuel utilization shifts, (b) pollution shifts, and (c) total cost for consumers. In the second study, the impact on distribution transformers is quantified through a loss of-life (LOL) calculation that is based on the transformers hot-spot temperature. In (Hutson et al, 2008), an intelligent method has been proposed for scheduling the use of available energy storage capacity from GVs.

This paper presents the best framework of utilizing GVs to reduce the GHGs emission and generation cost . Actually, it is indicated that employing GVs in an inappropriate outline without providing the necessary infrastruscture may increase the total emission due to the increased load grid caused by connecting GVs and as a result, consuming more fossil fuels by thermal power plants to supply increased demand. This increase in emission of power plants could be higher than corresponding decrease by fleet transportation, thus, the net emission changing will be positive i.e. emission will increase. Economically, engaging GVs in an unsuitable scenario can impose incremental costs due to the increased load demand. New power plants will be needed to supply the peak load if it is greatly increased which may be very costly. In this paper, smart grid framework has been proposed as the most suitable way to incorporate GVs because it makes a better use of RESs that can help to solve the problem since renewable resources use any fossil fuels that make them cheaper and cleaner than traditional types. It is shown that implementation of RESs (wind and solar) will lead to reduce production cost and emission. In order to obtain precise and more realistic results, a new model of Wind Farms (WFs) is used for optimal power dispatch among units. Since the proposed cost function of WF in this paper is nonlinear and cannot be solved by analytical methods, evolutionary algorithms must be applied to solve the problem. Prior research using the genetic-algorithm (GA) and simulated annealing (SA) techniques has provided effective solutions for multi-objective optimization problem (Moghadasi, A.H. et al, 2011 and Heydari, H., 2011). In this paper, the particle swarm optimization (PSO) algorithm (Kennedy and Eberhart, 1995) is utilized due to its high ability in finding best result.
The rest of this paper is organized as follows. Section II describes problem formulations. To avoid redundant repetition, concepts related to the economic dispatch(ED) and PSO which are known and mentioned in many papers, are briefly explained in this section. In section III, PSO is applied to the ten units system in different scenarios to investigate the influence of GVs and RESs on cost and emission. Finally, the conclusion is given in section IV.

\section{Problem Formulation}

In this section, ED, WF cost function and PSO formulations are expressed in brief.

\section{Combined Economic Emission Dispatch (CEED)}

In this study, the objective function is composed of two terms, generation cost and emission, as given in (1). For a specified power plant, both cost and emission can be expressed as a polynomial function separately. The order of these functions depends on the intended accuracy. In this paper, a quadratic function is considered for cost and emission function as described in (2) and (3), respectively. This problem handles power balance equation (4) and power generation limits (5) are considered as physical and operating constraints (Venkatesh et al, 2003), (Liu, 2011).

$$
\begin{gathered}
O F=\omega_{1} T C+\omega_{2} T E \\
T C=\sum_{i=1}^{n} a_{i}+b_{i} P_{i}+c_{i} P_{i}^{2} \\
T E=\sum_{i=1}^{n} \alpha_{i} P_{i}^{2}+\beta_{i} P_{i}+\gamma_{i} \\
D=\sum_{i=1}^{n} P_{i} \\
P_{i_{\min }} \leq P_{i} \leq P_{i_{\max }}
\end{gathered}
$$

where $\mathrm{OF}$, TC and TE are objective function, total cost and total emission, respectively. $\omega_{1}$ and $\omega_{2}$ are weight factors. $a_{i}, b_{i}$ and $c_{i}$ are the positive fuel cost coefficients of unit $i . \alpha_{\mathrm{i}}, \beta_{\mathrm{i}}$ and $\gamma_{\mathrm{i}}$ are GHGs emission coefficients for unit $i$.

\section{Wind Farm (WF) Cost Function}

In some literatures, WF is modeled as a negative load without any cost (Yong et al, 2007), (Farhat and ElHawary, 2010) but it is not compatible with reality due to the uncertain nature of wind and output of the WF. Underestimation and overestimation of the available wind energy which may happen as a result of WF's bad modeling can imposes additional costs to private 
company owner that participate in electricity market and sell their power to customer by means of Independent System Operator (ISO). For this reason, it is necessary to model WF more detailed and accurate. In this study, authors use a new cost function in ED formulation. In this model, three cost functions form the main wind cost function that described in (6) (Jadhav and Roy, 2013).

$C=\sum_{i=1}^{N} C_{w, i}\left(w_{i}\right)+\sum_{i=1}^{N} C_{p, w, i}\left(W_{i, a v}-w_{i}\right)+\sum_{i=1}^{N} C_{r, w, i}\left(w_{i}-W_{i, a v}\right)$

where $\mathrm{N}, \mathrm{w}_{\mathrm{i}}, \mathrm{W}_{\mathrm{i}, \mathrm{av}}$ and $\mathrm{W}_{\mathrm{r}, \mathrm{i}}$ are number of wind farms, scheduled wind power from the ith WF, available wind power from the ith WF and rated wind power from the ith WF, respectively.

In (6), the first term is the cost that system operator must pay to the WF's owner against generated power. This cost function is modeled linearly as indicated in (7).

$$
C_{w, i}\left(w_{i}\right)=d_{i} w_{i}
$$

where $d_{i}$ is the direct cost coefficient for ith wind farm. In (Jadhav and Roy, 2013), it has been shown that the total cost of wind generation is around $57 \%$ of that for thermal one. Consequently, this cost coefficient can be chosen accordingly in optimal dispatch formulation.

Second and third part of (6) is related to the uncertainty nature of wind power output given in (8) and (9). (8) is considered as a penalty cost function for not using all the available wind power which assumed to be linearly related to the difference between the $\mathrm{W}_{\mathrm{i}, \text { av }}$ and $\mathrm{W}_{\mathrm{i}}$. The reserve requirement cost is due to being $\mathrm{W}_{\mathrm{i}, \text { av }}$ less than the $\mathrm{W}_{\mathrm{i}}$. It is similar to penalty cost. If the WF is not owned by the system operator, the direct cost coefficient and penalty cost may be zero. The power Probability Density Function (PDF) of the wind energy conversion system (WECS)output power that indicated by $\mathrm{f}_{\mathrm{w}}(\mathrm{w})$ in (10) is obtained by wellknown two-parameter Weibull function dependent on wind speed and probability theory for random variables. More detailed information about the formulation of wind cost function is given in (Juliana and Sauer, 2013). Estimating methods of Weibull shape and scale factors $(\mathrm{k} \& \mathrm{c})$ using the available wind speed data are given in (Seguro and Lambert, 2000 ).

The PDF of Weibull function are illustrated in Fig.1 for different $\mathrm{k}$ and $\mathrm{c}$ parameters.

$$
\begin{aligned}
& C_{p, w, i}\left(W_{i, a v}-w_{i}\right)=k_{p, i}\left(W_{i, a v}-w_{i}\right)=k_{p, i} \int_{w_{i}}^{w_{r i}}\left(w-w_{i}\right) f_{w}(w) d \\
& +k_{p, i} w_{i}\left\{\exp \left(-\left(\frac{v_{r}}{c}\right)^{k}\right)-\exp \left(-\left(\frac{v_{o}}{c}\right)^{k}\right)\right\} \\
& C_{r, w, i}\left(w_{i}-W_{i, a v}\right)=k_{r, i}\left(w_{i}-W_{i, a v}\right)=k_{r, i} \int_{0}^{w_{i}}\left(w_{i}-w\right) f_{w}(w) d v \\
& +k_{r, i} w_{i}\left\{1-\exp \left(-\left(\frac{v_{i}}{c}\right)^{k}\right)+\exp \left(-\left(\frac{v_{o}}{c}\right)^{k}\right)\right\} \\
& f_{w}(w)=\frac{k l v_{i}}{w_{r} c}\left(\frac{(1+\rho l) v_{i}}{c}\right)^{(k-1)} \times \exp \left(-\left(\frac{(1+\rho l) v_{i}}{c}\right)^{k}\right)
\end{aligned}
$$

where $k_{p, i}$ and $k_{r, i}$ are penalty and reserve cost coefficients due to the underestimation and overestimation of wind power for $i_{\text {th }} \mathrm{WF}$ in $\$ / \mathrm{MW}$ repectively. $\mathrm{v}, \mathrm{Q}=\mathrm{W} / \mathrm{Wi}_{\mathrm{i}}$ and $\mathrm{l}=\left(\mathrm{V}_{\mathrm{r}}-\mathrm{V}_{\mathrm{i}}\right) / \mathrm{vi}$ are wind speed, ratio of wind power output to rated wind power and ratio of linear range of wind speed to cut-in wind speed repectively.

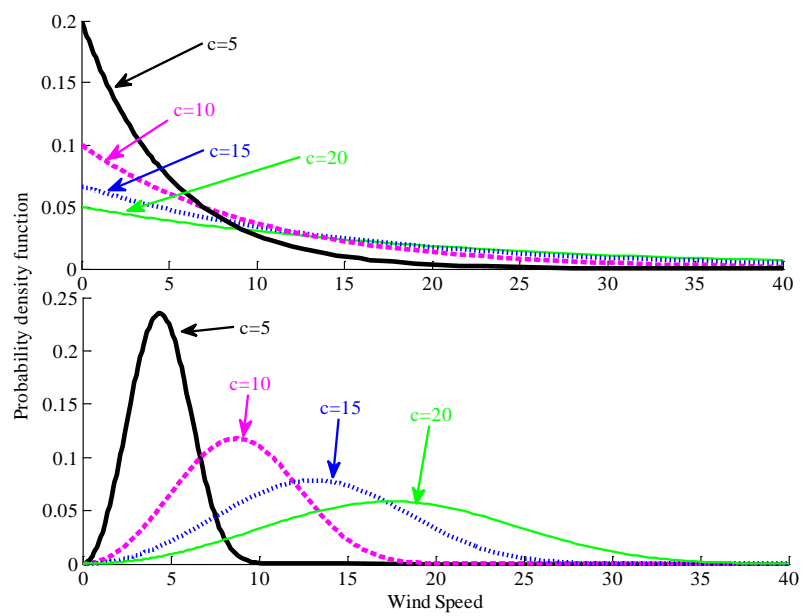

FIG. 1 PDF OF WEIBULL FUNCTION FOR DIFFERENT K AND C PARAMETERS

\section{Case Study}

To investigate the effectiveness of the proposed model, a ten-unit system with $50,000 \mathrm{GVs}$ is simulated using MATLAB 2011a software. The number of vehicles for this system has been calculated based on an approximate method which offered in (Roe and Meisel, 2008). The capacity of solar and WFs is considered 40 MW and 30 MW respectively. Calculations are executed on a $3.2 \mathrm{GHz}$, Core i5 processor with $4 \mathrm{~GB}$ RAM. The generators parameters and load data are given in table 2 (Ting et al, 2006).

Solar insolation and wind speed data are obtained from NREL. The WF parameters are given in Table 2. Other parameters' values used in this paper are as 
TABLE 1 GENERATOR SYSTEM OPERATOR DATA

\begin{tabular}{|c|c|c|c|c|c|c|c|c|c|c|}
\cline { 2 - 10 } \multicolumn{1}{c|}{} & Unit 1 & Unit 2 & Unit 3 & Unit 4 & Unit 5 & Unit 6 & Unit 7 & Unit 8 & Unit 9 & Unit 10 \\
\hline Pmax (MW) & 455 & 455 & 130 & 130 & 162 & 80 & 85 & 55 & 55 & 55 \\
\hline Pmin (MW) & 150 & 150 & 20 & 20 & 25 & 20 & 25 & 10 & 10 & 10 \\
\hline $\mathbf{a}(\mathbf{\$} / \mathbf{h})$ & 1000 & 970 & 700 & 680 & 450 & 370 & 480 & 660 & 665 & 670 \\
\hline $\mathbf{b}(\mathbf{\$} / \mathbf{M W h )}$ & 16.19 & 17.26 & 16.6 & 16.5 & 19.7 & 22.26 & 27.74 & 25.92 & 27.27 & 27.79 \\
\hline $\mathbf{c}(\mathbf{\$} / \mathbf{M W h 2 )}$ & 0.00048 & 0.00031 & 0.002 & 0.00211 & 0.00398 & 0.00712 & 0.0079 & 0.00413 & 0.00222 & 0.00173 \\
\hline $\boldsymbol{\alpha}($ ton/h) & 10.33908 & 10.33908 & 30.0391 & 30.0391 & 32.00006 & 32.00006 & 33.00056 & 33.00056 & 35.00056 & 36.00012 \\
\hline $\boldsymbol{\beta}$ (ton/MWh) & -0.24444 & -0.24444 & -0.4069 & -0.4069 & -0.38132 & -0.38132 & -0.39023 & -0.39023 & -0.39524 & -0.39864 \\
\hline $\boldsymbol{\gamma}$ (ton/MWh2) & 0.00312 & 0.00312 & 0.00509 & 0.00509 & 0.00344 & 0.00344 & 0.00465 & 0.00465 & 0.00465 & 0.0047 \\
\hline
\end{tabular}

TABLE 2 PARAMETER OF WF

\begin{tabular}{|c|c|c|c|c|c|c|}
\hline $\begin{array}{c}\mathrm{Wr} \\
(\mathrm{MW})\end{array}$ & $\begin{array}{c}\text { Vin } \\
(\mathrm{m} / \mathrm{s})\end{array}$ & $\begin{array}{c}\mathrm{Vr} \\
(\mathrm{m} / \mathrm{s})\end{array}$ & $\begin{array}{c}\text { Vout } \\
(\mathrm{m} / \mathrm{s})\end{array}$ & $\begin{array}{c}\mathrm{d} \\
(\$ / \mathrm{MW})\end{array}$ & $\begin{array}{c}\mathrm{kp}_{\mathrm{p}} \\
(\$ / \mathrm{MW})\end{array}$ & $\begin{array}{c}\mathrm{kr} \\
(\$ / \mathrm{MW})\end{array}$ \\
\hline 30 & 5 & 15 & 45 & 7 & 6 & 10 \\
\hline
\end{tabular}

follows: charging-discharging frequency $=1$ per day; scheduling period=24 hrs; for PSO, swarm size $=50$, iterations $=1000$, and accelerating parameters are $C_{1}=1.5$, $\mathrm{C}_{2}=2$ and finally Range $=0.5$. The average distance driven by each GV in a year and its needed energy are assumed 12000 mile and 8.22 KWh per day respectively. According to the average GV's emission of $445 \mathrm{gram} / \mathrm{mile}$, it is concluded that GHGs emission produced by a GV will be 5340000 gram per year. Therefore; the total emission from 50,000 GVs will be 267,000ton per year (Seguro and Lambert, 2000 ), (UEPA).

In this paper, to show the effect of GVs and renewable energy sources on the electricity and transportation industries, five scenarios are considered: 1) without GVs and renewable energy sources, 2) with GVs considering load leveling, 3) with GVs and WF, 4) with GVs and solar farm 5) with GVs and renewable sources (solar and wind simultaneously). Last three scenarios are referred to as "smart grid model" by the authors.

\section{Without GVs and Renewable Energy Sources}

First, PSO is applied to the ten-unit system without considering GVs and RESs for 24 hours to find optimal power dispatch according to the CEED objective function.

\section{With GVs Considering Load Levelling}

In this case, GVs are just charged through conventi- onal generation units using load-leveling optimization and don't have a bidirectional power flow with the grid. The purpose of GVs in this scenario is to increase the load level at off-peak hours in order to make the load curve flatter. The load profile is shown in Fig.2, before and after load leveling. cost and emission are calculated considering the load demand from 50,000 GVs and leveling the extra load. The obtained results for this scenario is given in Table 3.

By comparing scenario1 and 2, it can be inferred that daily emission is increased for 763.32 ton (21685.7 20922.38 ton) with considering load leveling. This extra emission (763.32 ton) which generated by power plants is to supply energy demand of 50,000 GVs during $24 \mathrm{hrs}$. Thus, the extra emission is 278611.8 tons $(763.32$ ton $\times 365)$ per year in addition to 267,000 tons from the transportation sector. Moreover, decreasing system efficiency and increasing losses caused by added load will result into additional emission term that must be added to this value. Therefore, as it was shown, load leveling by GVs will not lead to GHGs emission reduction, and even will increase it.

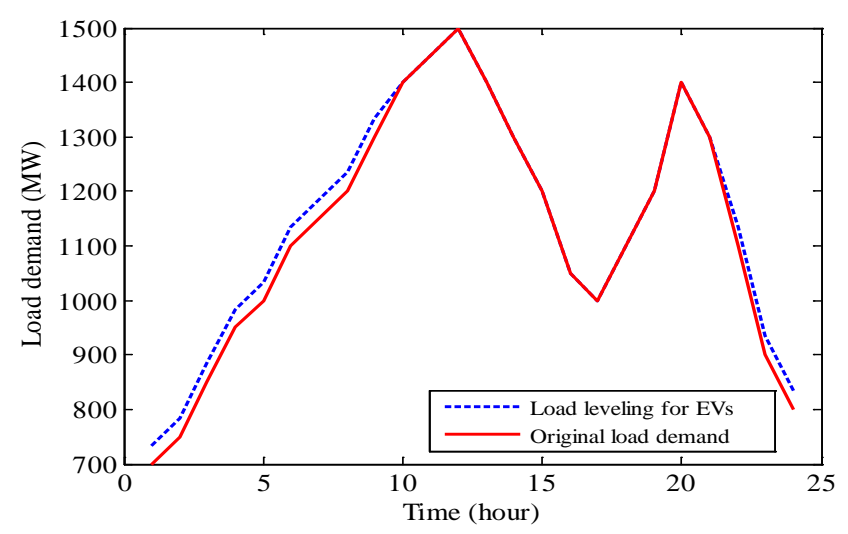

FIG. 2 EFFECT OF EVS ON THE LOAD PROFILE 
TABLE 3 EMISSION AND COST FROM TEN-UNIT SYSTEM WITH GVS CONSIDERING LOAD LEVELING

\begin{tabular}{|c|c|c|c|c|c|c|c|c|c|c|c|c|c|}
\hline Time & $\begin{array}{l}\text { Demand } \\
\text { (MW) }\end{array}$ & $\begin{array}{c}\text { P1 } \\
\text { (MW) }\end{array}$ & $\begin{array}{c}\text { P2 } \\
\text { (MW) }\end{array}$ & $\begin{array}{c}\text { P3 } \\
\text { (MW) }\end{array}$ & $\begin{array}{c}\text { P4 } \\
\text { (MW) }\end{array}$ & $\begin{array}{c}\text { P5 } \\
\text { (MW) }\end{array}$ & $\begin{array}{c}\text { P6 } \\
\text { (MW) }\end{array}$ & $\begin{array}{c}\text { P7 } \\
\text { (MW) }\end{array}$ & $\begin{array}{c}\text { P8 } \\
\text { (MW) }\end{array}$ & $\begin{array}{c}\text { P9 } \\
\text { (MW) }\end{array}$ & $\begin{array}{l}\text { P10 } \\
\text { (MW) }\end{array}$ & $\begin{array}{c}\text { Emission } \\
\text { (ton) }\end{array}$ & $\begin{array}{c}\text { Fuel } \\
\text { Cost (\$) }\end{array}$ \\
\hline 1 & 734.3 & 429.10 & 150.03 & 20.01 & 35.17 & 25 & 20 & 25 & 10 & 10 & 10 & 739.84 & 19644.81 \\
\hline 2 & 784.3 & 226.42 & 175.784 & 129.89 & 129.97 & 47.235 & 20 & 25 & 10 & 10 & 10 & 472.03 & 20645.54 \\
\hline 3 & 884.3 & 264.218 & 212.837 & 130 & 130 & 72.245 & 20 & 25 & 10 & 10 & 10 & 557.39 & 22417.37 \\
\hline 4 & 984.3 & 299.002 & 251.39 & 130 & 130 & 98.907 & 20 & 25 & 10 & 10 & 10 & 661.96 & 24204.31 \\
\hline 5 & 1034.3 & 318.595 & 268.744 & 130 & 130 & 111.95 & 20.01 & 25 & 10 & 10 & 10 & 723.33 & 25097.78 \\
\hline 6 & 1134.3 & 350.418 & 301.232 & 130 & 130 & 132.52 & 35.13 & 25 & 10 & 10 & 10 & 838.37 & 26957.43 \\
\hline 7 & 1184.3 & 365.591 & 315.418 & 130 & 130 & 143.4 & 44.89 & 25 & 10 & 10 & 10 & 897.52 & 27904.99 \\
\hline 8 & 1234.3 & 380.446 & 330.843 & 130 & 130 & 154.52 & 53.49 & 25 & 10 & 10 & 10 & 962.59 & 28849.83 \\
\hline 9 & 1334.3 & 416.972 & 367.737 & 130 & 130 & 162 & 72.59 & 25 & 10 & 10 & 10 & 1122.22 & 30699.04 \\
\hline 10 & 1400 & 444.568 & 398.432 & 130 & 130 & 162 & 80 & 25 & 10 & 10 & 10 & 1256.59 & 31867.30 \\
\hline 11 & 1450 & 455 & 438 & 130 & 130 & 162 & 80 & 25 & 10 & 10 & 10 & 1376.90 & 32733.90 \\
\hline 12 & 1500 & 455 & 455 & 130 & 130 & 162 & 80 & 25 & 43 & 10 & 10 & 1415.37 & 33894.61 \\
\hline 13 & 1400 & 445.265 & 397.735 & 130 & 130 & 162 & 80 & 25 & 10 & 10 & 10 & 1256.79 & 31866.67 \\
\hline 14 & 1300 & 403.184 & 354.54 & 130 & 130 & 162 & 65.28 & 25 & 10 & 10 & 10 & 1063.11 & 30069.65 \\
\hline 15 & 1200 & 370.194 & 321.896 & 130 & 130 & 146.17 & 46.74 & 25 & 10 & 10 & 10 & 919.84 & 28194.34 \\
\hline 16 & 1050 & 324.473 & 274.856 & 130 & 130 & 114.72 & 20.95 & 25 & 10 & 10 & 10 & 743.44 & 25379.56 \\
\hline 17 & 1000 & 306.42 & 256.015 & 130 & 130 & 102.56 & 20 & 25 & 10 & 10 & 10 & 681.49 & 24482.10 \\
\hline 18 & 1100 & 338.867 & 290.955 & 130 & 130 & 125.75 & 29.43 & 25 & 10 & 10 & 10 & 797.35 & 26317.45 \\
\hline 19 & 1200 & 370.429 & 322.046 & 130 & 130 & 146.69 & 45.83 & 25 & 10 & 10 & 10 & 920.98 & 28190.95 \\
\hline 20 & 1400 & 444.962 & 398.038 & 130 & 130 & 162 & 80 & 25 & 10 & 10 & 10 & 1256.70 & 31866.95 \\
\hline 21 & 1300 & 402.322 & 355.237 & 130 & 130 & 162 & 65.44 & 25 & 10 & 10 & 10 & 1062.54 & 30071.37 \\
\hline 22 & 1134.3 & 351.649 & 301.742 & 130 & 130 & 132.05 & 33.86 & 25 & 10 & 10 & 10 & 841.53 & 26948.00 \\
\hline 23 & 934.3 & 281.202 & 232.432 & 130 & 130 & 85.665 & 20 & 25 & 10 & 10 & 10 & 606.75 & 23310.52 \\
\hline 24 & 834.3 & 245.335 & 193.225 & 130 & 130 & 60.74 & 20 & 25 & 10 & 10 & 10 & 511.06 & 21533.32 \\
\hline & & & & & & & & & & & Total & 21685.70 & 653147.79 \\
\hline
\end{tabular}

\section{Smart Grid Model}

The effect of RESs on production cost and emission through three different scenarios is investigated in this section.

\section{1) With GVs and WF}

In this scenario, WF is added to conventional units and GVs are charged as loads and discharged into the grid as sources. PSO successfully employed to analyze the effect of WF on cost and emission. The total production cost and emission will be 638933.23 \$ and 20197.48 tons. Based on the obtained results, the emission and generation cost has been reduced because of utilizing clean and cheap energy of wind to supply a part of grid's demand.

\section{2) With GVs and Solar Farm}

The WF is replaced with a solar farm in this case. The total production cost and emission will be $641026 \$$ and 20255.7 tons. The solar energy is not available in all day long (only available from $7 \mathrm{AM}$ to $4 \mathrm{PM}$ ) while WF can generate energy in $24 \mathrm{hrs}$. For this reason, although the rated power of solar
$\mathrm{PV}$ is greater than that of wind power, the total generated energy by PV plant is less than wind type and consequently, production cost and emission in this scenario will be higher than wind scenario.

\section{3) With GVs and Renewable Sources (Solar and Wind Simultaneously)}

Finally, results from a smart grid model with wind, solar and GVs are shown in Table II, where GVs operate as loads and sources. Moreover, uncertainties of wind and solar sources, load and variable exchanged power between GVs and grid are considered.

According to Table 4, GVs are charged from the grid at off-peak load during the 1st-7th, 16th-18th, and 22nd-24th hours. On the other hand, GVs are discharged into the grid at peak load during the 8th-15th and 19th-21st hours.

Fig. 3 and Fig. 4 illustrate the comparison of the proposed scenarios with respect to emission and cost respectively. As it is demonstrated in these figures, fifth scenario is preferable because of less GHGs emission and cost caused by supplying a part of the grid's demand by RESs. 


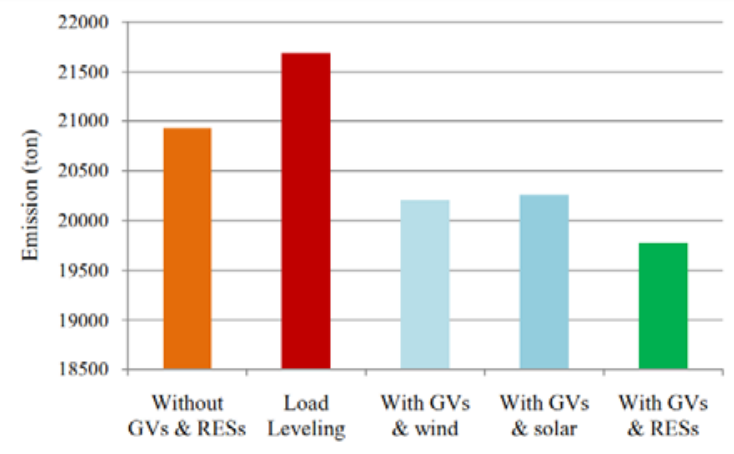

FIG. 3 COMPARISON OF THE PROPOSED SCENARIOS IN EMISSION

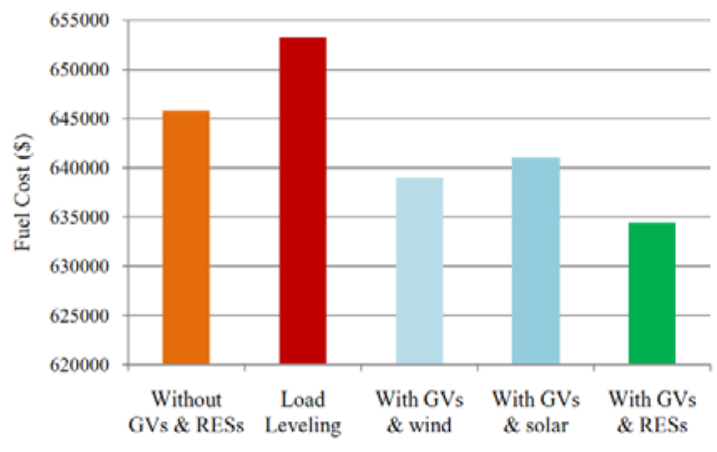

FIG. 4 COMPARISON OF THE PROPOSED SCENARIOS IN FUEL COST

TABLE 4. DISPATCH OF CONVENTIONAL UNITS AND RESS CONSIDERING GVS AS LOADS AND SOURCES IN SMART GRID

\begin{tabular}{|c|c|c|c|c|c|c|c|c|c|c|c|c|c|c|c|}
\hline Time & $\begin{array}{c}\text { Demand } \\
\text { (MW) }\end{array}$ & $\begin{array}{c}\text { V2G/G2V } \\
\text { (MW) }\end{array}$ & $\begin{array}{c}\text { P1 } \\
\text { (MW) }\end{array}$ & $\begin{array}{c}\text { P2 } \\
\text { (MW) }\end{array}$ & $\begin{array}{c}\text { P3 } \\
\text { (MW) }\end{array}$ & $\begin{array}{c}\text { P4 } \\
\text { (MW) }\end{array}$ & $\begin{array}{c}\text { P5 } \\
\text { (MW) }\end{array}$ & $\begin{array}{c}\text { P6 } \\
\text { (MW) }\end{array}$ & $\begin{array}{c}\text { P7 } \\
\text { (MW) }\end{array}$ & $\begin{array}{c}\text { P8 } \\
\text { (MW) }\end{array}$ & $\begin{array}{c}\text { P9 } \\
\text { (MW) }\end{array}$ & $\begin{array}{c}\text { P10 } \\
\text { (MW) }\end{array}$ & $\begin{array}{l}\text { Wind } \\
\text { (MW) }\end{array}$ & $\begin{array}{c}\text { Emission } \\
\text { (ton) }\end{array}$ & $\begin{array}{c}\text { Fuel Cost } \\
\text { (\$) }\end{array}$ \\
\hline 1 & 700 & -22.96 & 204.58 & 151.08 & 120.16 & 121.78 & 33.72 & 20 & 25 & 10 & 10 & 10 & 16.64 & 414.65 & 19282.07 \\
\hline 2 & 750 & -19.09 & 221.26 & 166.00 & 120.52 & 122.55 & 38.94 & 20 & 25 & 10 & 10 & 10 & 24.78 & 444.08 & 19939.14 \\
\hline 3 & 850 & -15.66 & 244.51 & 199.29 & 130 & 129.91 & 63.30 & 20 & 25 & 10 & 10 & 10 & 23.64 & 515.99 & 21675.62 \\
\hline 4 & 950 & -22.16 & 285.52 & 240.58 & 130 & 130 & 92.33 & 20 & 25 & 10 & 10 & 10 & 18.73 & 624.90 & 23659.49 \\
\hline 5 & 1000 & -25.15 & 313.34 & 269.45 & 129.85 & 130 & 104.83 & 20.57 & 25 & 10 & 10 & 10 & 2.09 & 712.41 & 24887.49 \\
\hline 6 & 1100 & -17.52 & 341.99 & 294.55 & 130 & 129.97 & 126.58 & 31.79 & 25 & 10 & 10 & 10 & 7.65 & 808.87 & 26501.79 \\
\hline 7 & 1150 & -14.08 & 351.83 & 306.05 & 130 & 130 & 137.66 & 40.67 & 25 & 10 & 10 & 10 & 12.78 & 851.20 & 27297.92 \\
\hline 8 & 1200 & 28.32 & 350.13 & 299.90 & 129.99 & 130 & 131.29 & 37.08 & 25 & 10 & 10 & 10 & 20.82 & 834.71 & 26948.45 \\
\hline 9 & 1300 & 31.07 & 374.92 & 336.72 & 130 & 130 & 148.62 & 55.85 & 25 & 10 & 10 & 10 & 6.36 & 957.79 & 28792.47 \\
\hline 10 & 1400 & 23.77 & 418.26 & 367.09 & 130 & 129.99 & 161.49 & 67.56 & 25 & 10 & 10 & 10 & 10.79 & 1123.04 & 30582.40 \\
\hline 11 & 1450 & 20.56 & 432.49 & 387.03 & 130 & 130 & 161.81 & 77.18 & 25 & 10 & 10 & 10 & 17.85 & 1200.75 & 31397.74 \\
\hline 12 & 1500 & 73.1 & 431.37 & 382.07 & 129.99 & 130 & 162 & 77.99 & 25 & 10 & 10 & 10 & 22.54 & 1187.56 & 31314.87 \\
\hline 13 & 1400 & 15.03 & 410.34 & 361.83 & 130 & 129.99 & 162 & 69.00 & 25 & 10 & 10 & 10 & 30 & 1094.33 & 30402.77 \\
\hline 14 & 1300 & 16.76 & 375.41 & 332.80 & 130 & 130 & 151.27 & 51.14 & 25 & 10 & 10 & 10 & 26.03 & 953.38 & 28678.77 \\
\hline 15 & 1200 & 15.08 & 357.30 & 305.26 & 130 & 130 & 133.65 & 38.36 & 25 & 10 & 10 & 10 & 25.64 & 858.71 & 27238.73 \\
\hline 16 & 1050 & -21.43 & 323.46 & 264.91 & 130 & 130 & 110.32 & 21.81 & 25 & 10 & 10 & 10 & 22.99 & 725.39 & 25118.82 \\
\hline 17 & 1000 & -37.33 & 321.31 & 257.26 & 129.97 & 130 & 104.66 & 20 & 25 & 10 & 10 & 10 & 19.13 & 709.37 & 24791.87 \\
\hline 18 & 1100 & -16.27 & 334.42 & 295.20 & 130 & 129.98 & 124.66 & 30.32 & 25 & 10 & 10 & 10 & 16.66 & 795.11 & 26316.33 \\
\hline 19 & 1200 & 19.34 & 358.34 & 307.34 & 130 & 130 & 137.92 & 44.30 & 25 & 10 & 10 & 10 & 17.70 & 866.00 & 27517.92 \\
\hline 20 & 1400 & 50.73 & 418.79 & 366.76 & 130 & 130 & 161.99 & 70.56 & 25 & 10 & 10 & 10 & 16.16 & 1124.30 & 30664.93 \\
\hline 21 & 1300 & 24.98 & 393.85 & 346.47 & 130 & 130 & 161.46 & 58.23 & 25 & 10 & 10 & 10 & 0.01 & 1025.80 & 29599.54 \\
\hline 22 & 1100 & -15.59 & 342.39 & 291.07 & 130 & 130 & 128.57 & 34.98 & 25 & 10 & 10 & 10 & 3.58 & 804.66 & 26562.22 \\
\hline 23 & 900 & -35.22 & 282.02 & 232.78 & 130 & 130 & 82.47 & 20.01 & 25 & 10 & 10 & 10 & 2.93 & 607.77 & 23265.48 \\
\hline 24 & 800 & -56.28 & 255.55 & 199.71 & 129.99 & 130 & 66.02 & 20 & 25 & 10 & 10 & 10 & 0 & 531.17 & 21920.61 \\
\hline & & & & & & & & & & & & & Total & 19771.93 & 634357.42 \\
\hline
\end{tabular}

\section{Conclusion}

In this paper, influence of GVs and RESs on production cost and emission of electricity and transportation industries is investigated comprehensively. A combined economic emission objective function is used for optimal power dispatch among network units. Obtained results by PSO algorithm prove that using GVs without any sustainable energy resources may increases net emission of both industries. However, this increase was just calculated in load leveling framework while connecting GVs to the grid at off-peak hours for charging will even result into more increase than before. Moreover, as it was anticipated, using RESs in power system reduces cost and emission. In this regard, wind energy has more ability for this purpose due to its more availability in same rated power plant.

\section{REFERENCES}

Amini, M.H. et al, "Load management using multi-agent systems in smart distribution network," IEEE PES General Meeting, Vancouver, BC, Canada, 2013. 
Amini, M.H., Nabi, B., Parsa Moghadam, M., Mortazavi, S.A., " Evaluating the Effect of Demand Response Programs and Fuel Cost on PHEV Owners Behavior, A Mathematical Approach", Second Iranian Conference on Smart Grid, 2012.

Department of Energy \& Climate Change (DECC), "Smarter grids: the opportunity," Available online at http://www.decc.gov.uk.

Farhadi, M.; Mohammed, O., "Realtime Operation and Harmonic Analysis of Isolated and Non-Isolated Hybrid DC Microgrid," Industry Applications, IEEE Transactions on , vol.PP, no.99, pp.1,1.

Farhat, I.A., El-Hawary, M.E., “Dynamicadaptive bacterial foraging algorithmfor optimum economic dispatch withvalve-point effects and wind power", IET Gener. Transm. Distrib., 2010, Vol. 4, Iss. 9, pp. 989-999

Hadley, S. W. and Tsvetkova ,A., "Potential impacts of plugin hybrid electric vehicles on regional power generation," Oak Ridge National Laboratory, Oak Ridge, TN , ORN L/T M-2007/150, Jan. 2008.

Hutson, C., Venayagamoorthy, G.K. and Corzine, K.A., "Intelligent Scheduling of Hybrid and Electric Vehicle Storage Capacity in a Parking Lot for Profit Maximization in Grid Power Transactions", IEEE Energy 2030, Atlanta, GA USA, 17-18 November, 2008

Institute for Local Self-Reliance available online website, http://www.ilsr.org

Jadhav, H.T., Roy, Ranjit, Gbest guided artificial bee colony algorithm for environmental/economic dispatch considering wind power, Expert Systems with Applications 40 (2013), pp. 6385-6399

Juliana, F. C. R., \& Sauer, I. L. “An assessment of wind power prospects in theBrazilian hydrothermal system", Renewable and Sustainable Energy Reviews, 2013, 19, pp. 742-753.

Kempton ,W. and Tomic, J., "Vehicle-to-grid implementation: From stabilizing the grid to supporting large-scale renewable energy", Power Source Journal, vol. 144, no. 1, pp. 2 80-294, 2005.
Kempton, W. and Tomic, J., "Vehicle-to-grid power fundamentals: Calculating capacity and net revenue," Power Source Journal, vol.144, no. 1, pp. 268-279, 2005.

Kennedy, J. and Eberhart, R., "Particle swarm optimazation, "inProc.IEEE Int.Conf.Neural Networks (ICNN'95), vol.IV, Perth, Australia, 1995, pp. 1942-1948

Liu, X., “Emission minimisation dispatch constrained by costand wind power", IET Gener. Transm. Distrib., 2011, Vol. 5, Iss. 7, pp. 735-742

Meliopoulos, S., Meisel, J., Cokkinides, G., and Overbye, T., "Power system level impacts of plug-in hybrid vehicles," PSerc Project, Final Report, Oct. 2009 [Online]. Available at: http ://www.pserc.wisc.edu /documents/publications /reports/2009_ reports/

Moghadasi, A.H.; Heydari,H.;Farhadi,M.,"Pareto Optimality for the Design of SMES Solenoid Coils Verified by Magnetic Field Analysis," Applied Superconductivity, IEEE Transactions on , vol.21, no.1, pp.13,20, Feb. 2011

Heydari, H.; Moghadasi, A.H., "Optimization Scheme in Combinatorial UPQC and SFCL Using Normalized Simulated Annealing," Power Delivery, IEEE Transactions on, vol.26, no.3, pp.1489,1498, July 2011.

Mitlitski Jerry, "Raising the Volt-Age: Is Obama's Goal of 1 Million Electric Vehicles on U.S. Highways by 2015 Realistic?", Scientific American. Retrieved 2012-05-11.

Masoum, A.S. et al, "Smart load management of plug-in electric vehicles indistribution and residential networks with chargingstations for peak shaving and loss minimisationconsidering voltage regulation", IET Gener. Transm. Distrib., 2013, Vol. 7, Iss. 8, pp. 866-873

National Renewable Energy Laboratory (NREL) Solar Radiation Research Laboratory (SRRL), Golden, CO. [Online]. Available: http://www.nrel.gov/midc/srrl_bms/

Parks, K., Denholm, P., and T. Markel, "Costs and emissions associated with plug-in hybrid electric vehicle charging in the Xcel Energy Colorado service territory," Nat. Renewable Energy Lab., Golden, CO, Tech. Rep. NREL/TP-640-41410, May 2007.

Renewable Energy Group websit ,http://www.renewableenergyworld.com 
Roe, Curtis, Meisel, Jerome, “Power System Level Impacts of Plug-In Hybrid Electric Vehicles Using Simulation Data",IEEE Energy 2030, Atlanta, GA USA, 17-18 November, 2008

Seguro, J. V. , Lambert, T. W., "Modern estimation of the parameters of the Weibull wind speed distribution for wind energy analysis," J. Wind Eng. Ind. Aerodyn., vol. 85, pp. 15-84, 2000.

Ting, T. O., Rao, M. V. C., and Loo, C. K., “A novel approach for unit commitment problem via an effective hybrid particle swarm optimization," IEEE Trans. Power Syst., vol. 21, no. 1, pp. 411-418, Feb. 2006.

United Nations Framework Convention on Climate change available online website, http://unfccc.int/2860.php

United state Enviromental Protection Agency, “Greenhouse Gas Emissions from a Typical Passenger Vehicle, Office of Transportation and Air Quality, EPA-420-F-11-041, December 2011

Venkatesh, P., Gnanadass, R.,and Padhy, N. P.,“Comparison and application of evolutionary programming techniques to combined economic emission dispatch with line flow constraints," IEEE Trans. Power Syst., vol. 18, no. 2, pp. 688-697, May 2003

Voelcker, John, “Electric-Car Charger Congestion...At Least in California". Green Car Reports. Retrieved 2013-02-27.

Wang, xifan, "modern power system planning", McGraw Hill ,1994.

Yong, Liu , Wuhan Univ., Wuhan, Tao, Shang, "Economic dispatch of power system incorporating wind power plant",International Power Engineering Conference, 2007

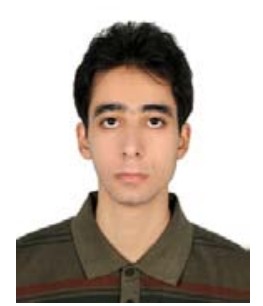

Amin Gholami received the B.Sc. degree in electrical engineering from Iran University of Science and Technology (IUST), Tehran, Iran, in 2013. He is currently with the Department of Electrical and Computer Engineering, University of Tehran as MS student. His research interests are integrating of renewable energy resources, Wide Area Monitoring System (WAMS), Power System Reliability and Power System Restoration

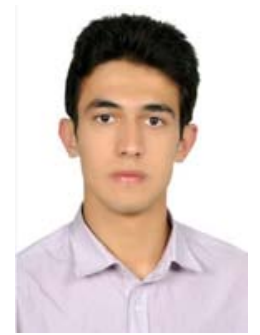

Mahdi Jamei (S'2013) was born in Shahrood, Iran. He received the B.Sc. degree in Electrical Engineering from Iran University of Science and Technology, Tehran, Iran, in 2013. He is currently working toward the M.Sc. in electrical engineering at Florida International University (FIU), Miami, USA. His research interests include cyber security of smart grid, smart distribution network, electric vehicles, power system control.

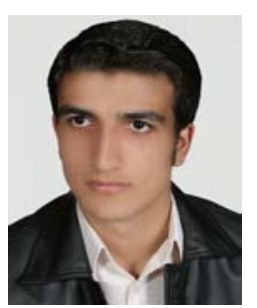

Javad Ansari received the B.Sc. degree in electrical engineering from Iran University of Science and Technology (IUST), Tehran, Iran, in 2012. He is currently with the Centre of Excellence for Power System Automation and Operation, Department of Electrical Engineering, Iran University of Science and Technology (IUST) as MS student. His current research interests include integration of renewable generation into power systems and control and operation of smart grids.

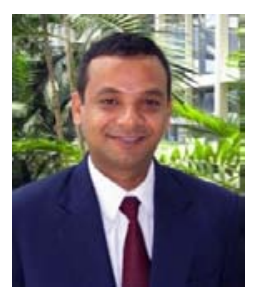

Arif I. Sarwat received his M.S. degree in Electrical and Computer Engineering from the University of Florida, Gainesville. In 2010, he received his Ph.D. degree in Electrical Engineering from the University of South Florida. Dr. Sarwat worked in the industry (SIEMENS) for nine years executing many critical projects. Before joining the Florida International University, he was Assistant Professor of Electrical Engineering at the University at Buffalo, the State University of New York (SUNY). He is co-developer of the DOE funded Gateway to Power (G2P) Project along with FPL/NextEra company. His significant work in Energy Storage, Micro-Grid and Demand Side Management (DSM) is demonstrated by Sustainable Electric Energy Delivery Systems in Florida. He is also coprinciple investigator in the study of reliability \& predictability of highly penetrated renewable resources power plants (DOE funded Sunshine State Solar Grid Initiative (SUNGRIN). His research areas are Smart Grids, High Penetration of Renewable Systems, Power System Reliability, Large Scale Distributed Generation Integration, Large Scale Data Analysis, Distributed Power Systems, Demand Side Management, Communication, Power System Optimization and Cyber Security. 